\title{
Association of protein intake with the change of lean mass among elderly women: The Osteoporosis Risk Factor and Prevention - Fracture Prevention Study (OSTPRE-FPS)
}

\author{
Masoud Isanejad ${ }^{1}$, Jaakko Mursu ${ }^{1}$, Joonas Sirola ${ }^{2,3}$, Heikki Kröger ${ }^{2,3}$, Toni Rikkonen ${ }^{3}$, \\ Marjo Tuppurainen ${ }^{4}$ and Arja T. Erkkilä ${ }^{1}$ \\ ${ }^{1}$ Institute of Public Health and Clinical Nutrition, University of Eastern Finland, PO Box 1627 Kuopio, Finland \\ ${ }^{2}$ Department of Orthopaedics and Traumatology, Kuopio University Hospital, Kuopio, Finland \\ ${ }^{3}$ Kuopio Musculoskeletal Research Unit (KMRU), University of Eastern Finland, Kuopio, Finland \\ ${ }^{4}$ Department of Obstetrics and Gynaecology, Kuopio University Hospital, Kuopio, Finland
}

(Received 7 July 2015 - Final revision received 10 October 2015 - Accepted 13 October 2015)

Journal of Nutritional Science (2015), vol. 4, e41, page 1 of 8

doi:10.1017/jns.2015.31

Abstract

Low protein intake can lead to declined lean mass (LM) in elderly. We examined the associations of total protein (TP), animal protein (AP) and plant protein (PP) intakes with LM. The association of TP intake with LM change was further evaluated according to weight change status. This cross-sectional and prospective cohort study included 554 women aged 68 (SD 1.9) years from the Osteoporosis Risk Factor and Prevention - Fracture Prevention Study (OSTPRE-FPS). The intervention group ( $(n$ 270) received daily cholecalciferol (800 IU; $20 \mu \mathrm{g}$ ) and $\mathrm{Ca}(1000 \mathrm{mg}$ ) for 3 years while the control group received neither supplementation nor placebo (n 282). Participants filled out a questionnaire on lifestyle factors and a 3-d food record in 2002 and underwent dual-energy X-ray absorptiometry for body composition measurements at baseline and 3 years. Multiple linear regressions evaluated the association between protein intake and LM, adjusting for relevant covariates. At the baseline TP and AP intakes were positively associated with LM and trunk LM, TP was associated also with appendicular LM (aLM). Follow-up results showed that in the total population and the intervention group, higher TP and AP were associated with increased LM and aLM $(P \leq 0 \cdot 050)$. No such associations were observed in the control group. PP intake was also associated with aLM change in the total population. Overall, the associations were independent of fat mass. Further, among weight maintainers, TP intake was positively associated with LM, aLM and trunk LM changes $(P \leq 0 \cdot 020)$. In conclusion, dietary TP, especially AP, intake may be a modifiable risk factor for sarcopenia by preserving LM in the elderly.

Key words: Dietary protein intake: Animal protein intake: Lean mass in elderly: Sarcopenia

The sarcopenic phenotype is characterised by an absolute or relative reduction in lean mass (LM) which can lead to increased risk of fractures, frailty and loss of independence ${ }^{(1,2)}$. Older adults over the age of 50 years lose approximately $1-2 \%$ of LM per year ${ }^{(3)}$. However, the aetiology of LM loss is multifactorial. Dietary protein intake has been considered as one potential contributor to LM change which can determine the balance between protein synthesis and the protein breakdown rate in muscles ${ }^{(2,4)}$. Current evidence suggests that age-related loss of LM may be halted or even reversed by increased daily protein intake ${ }^{(5-7)}$. The quality of protein intake additionally may play a role in determining the LM. Putatively, animal protein (AP) provides more essential amino acids in comparison with plant protein (PP) sources which can stimulate muscle

Abbreviations: aLM, appendicular lean mass; AP, animal protein; BW, body weight; FM, fat mass; LM, lean mass; MPS, muscle protein synthesis; PP, plant protein; TP, total protein.

* Corresponding author: M. Isanejad, email masoud.isanejad@uef.fi 
protein synthesis $(\mathrm{MPS})^{(8-10)}$. Vitamin D supplementation further might affect LM directly through different mechanisms. It has been suggested also that vitamin $\mathrm{D}$ supplementation might have a synergic relationship with dietary protein intake in increasing $\mathrm{LM}^{(11-15)}$. However, little is known regarding the interaction between vitamin $\mathrm{D}$ supplementation and dietary protein intake and LM and further studies are warranted.

Although data to support guideline for weight-loss treatment in elderly are limited, one of the main targets was the preservation of LM by adequate protein intake ${ }^{(16)}$. It is well known that dietary protein intake may affect LM and fat mass (FM) partitioning during weight loss ${ }^{(17)}$. Thus, evaluating the protein intake association with body composition during weight changes may have important implications among elderly who tend to lose weight.

The primary objective of the present study was to examine the associations of total protein (TP), AP and PP intakes with $\mathrm{LM}$ at baseline and changes over a 3-year follow-up among elderly women. A secondary objective was to evaluate the association of TP with change of LM according to weight-change status.

\section{Subjects and methods}

\section{Study population}

Data of the present study were collected from the Osteoporosis Risk Factor and Prevention - Fracture Prevention Study (OSTPRE-FPS), which was a 3-year intervention to investigate the effect of $\mathrm{Ca}$ and vitamin $\mathrm{D}$ supplementation on incidence of falls and fractures among elderly women. The subjects were drawn from the population-based OSTPRE cohort ${ }^{(18)}$. In total 3432 women volunteered to participate in the study, and 750 women were further randomly invited into this subsample for participating in detailed examinations including the measurement of body composition, and several clinical, physical and laboratory tests ${ }^{(19)}$. Of these, 554 returned valid food records and had valid body composition measurements for both the baseline and at the 3-year followup. The intervention group $(n 270)$ received daily cholecalciferol (800 IU; $20 \mu \mathrm{g}$ ) and $\mathrm{Ca}(1000 \mathrm{mg})$ for 3 years while the control group received neither supplementation nor placebo $(n \text { 282) })^{(18)}$. All participants provided written permission for participation. The study was approved in October 2001 by the ethical committee of Kuopio University Hospital. The study was registered in Clinical trials.gov by the identification NCT00592917 $7^{(18)}$.

\section{Body composition measurements}

Height and weight of participants were measured in light indoor clothing without shoes, and BMI was calculated $(\mathrm{kg} /$ $\mathrm{m}^{2}$ ). To measure body composition, whole-body dual-energy $\mathrm{X}$-ray absorptiometry scans were performed by specially trained nurses, using the same Lunar Prodigy adhering to the imaging and analysis protocols provided by the manufacturer (Lunar Co.) $)^{(20,21)}$. Appendicular LM (aLM) was calculated as the sum of the non-fat, non-bone skeletal muscle mass in arms and legs. Further, absolute changes in LM, aLM and trunk LM were calculated by subtracting the baseline values from those measured at year 3 .

\section{Dietary intakes}

Dietary intake was collected by using 3-d food records at baseline. A questionnaire and instructions were sent to participants beforehand, and they were returned on the visiting day. The questionnaire was for three consecutive days, including $2 \mathrm{~d}$ during the week and $1 \mathrm{~d}$ in the weekend (Saturday or Sunday). In the case of uncertainties in the food record, a nutritionist called the participant for additional information ${ }^{(22)}$. To assess the under-reporting the energy intake:estimated BMR ratio was calculated based on body weight (BW) according to equations given by the Department of Health in the $\mathrm{UK}^{(23)}$. The energy intake:BMR cut-off value for underreporting was chosen to be 1.49 , as derived from Goldberg et al. ${ }^{(24)}$ and Black $^{(25)}$ and none of the participants was excluded from the analyses. Nutritional intake from food was calculated using the Nutrica program (version 2.5; Finnish social insurance institute, Turku, Finland). Collected data provided calculations of AP (including eggs, dairy products, poultry and meat) and PP sources (cereals, vegetables and fruits) of protein in addition to TP intake.

\section{Potential confounders}

All lifestyle-related information was gathered by the selfadministered questionnaire. The questionnaire included questions on age, smoking status (never, former and current), alcohol consumption (portions per week), use of hormone therapy (never used and used) and self-reported vitamin D supplementation. Physical activity level was compiled from frequency of exercise (times per week) and mobility status (restricted or non-restricted). Women were classified as passive if they had restricted or no mobility and exercised $\leq 2$ times/ week and those with no mobility restriction and who exercised $>2$ times/week were classified as active.

\section{Statistical analysis}

All statistical analyses were executed using SPSS software version 21 for Windows (IBM Corp.). A result was significant if the $P$ value was $<0 \cdot 05$. The protein intakes (TP, AP and PP) were adjusted for energy intake utilising the residual method $^{(26)}$. An advantage of this method is that it provides a measure of protein intake which is independent of total energy intake. Energy-adjusted protein intake (g/d) was modelled as a continuous variable and categorised into quartiles. Protein intake $(\mathrm{g} / \mathrm{kg} \mathrm{BW})$ was calculated using crude protein intake divided by BW.

Continuous variables were compared across the quartiles of energy-adjusted TP intake using ANOVA and categorical variables using $\chi^{2}$ tests. Multiple linear regression models were performed to examine the association between protein intake $(\mathrm{g} / \mathrm{d})$ as the independent variable with body composition measures as dependent variables, including LM, aLM and trunk 
LM at the baseline and changes in them over 3 years of follow-up. Follow-up associations of protein intake with changes in LM, aLM and trunk LM over 3 years of follow-up were explored separately between the intervention and control groups. Tests for a linear trend across quartiles of protein intake were conducted by using the median value in each quartile as a continuous variable in the linear regression model.

Model 1 was adjusted for age, height, total energy intake, study group and in longitudinal setting for baseline LM variables. Model 2 was adjusted for variables in model 1 plus smoking, alcohol use, physical activity level and hormone therapy use. Model 3 was adjusted for variables in model 2 plus baseline FM for cross-sectional setting and change of FM in prospective setting in order to determine whether the associations were independent of FM. For the models for AP and PP, the AP and PP intakes were included in the same regression model to adjust for each other.

We also examined the association between energy-adjusted protein intake $(\mathrm{g} / \mathrm{d})$ with $\mathrm{LM}$ measurements according to weight-change status. Those who lost over $3 \%$ of their weight during the 3 years of follow-up were classified as weight losers, those who gained over $3 \%$ were classified as weight gainers, and those with moderate change as weight maintainers. This $3 \%$ cut-off was selected and applied to exceed the CV for dual-energy X-ray absorptiometry soft tissue mass ${ }^{(5,27)}$.

\section{Results}

The participants were $65 \cdot 3-71.6$ years old; mean age was $68 \cdot 0$ (sD 1.9) years (Table 1). The energy intake was 6560 (SD 1556) $\mathrm{kJ} / \mathrm{d}$ (1567 (sD 371) kcal), and mean total energy-adjusted protein intake was $68.2 \mathrm{~g} / \mathrm{d}$. Median TP intake as a percentage of total energy intake and protein $(\mathrm{g} / \mathrm{kg} \mathrm{BW})$ by quartiles from quartile 1 to quartile 4 were $14.2 \%(0.77 \mathrm{~g} / \mathrm{kg} \mathrm{BW}), 16.5 \%$ $(0.89 \mathrm{~g} / \mathrm{kg} \mathrm{BW}), 18.5 \%(0.91 \mathrm{~g} / \mathrm{kg} \mathrm{BW})$ and $20.1 \%(1.17$ $\mathrm{g} / \mathrm{kg} \mathrm{BW})$. Women in the first and third quartiles of energy-adjusted protein intake were more likely to use hormone therapy (46\%) as compared with women in the second and fourth quartiles. Total fat intake $(\mathrm{g} / \mathrm{d})$ was highest in quartile 4 and energy intake was significantly higher in higher quartiles of protein intake. TP and AP intakes were significantly higher in higher quartiles of protein intake, while no significant association was observed for PP intake.

Those in the second and fourth quartiles had higher BW as compared with those in the first and third quartiles. LM, aLM and trunk LM were significantly increased with higher protein intake (Table 1). The absolute LM, aLM and trunk LM changes over the 3 years were $+0.69,-0.27$ and $+0.48 \%$, respectively. Over the 3 years of follow-up, about $24 \%$ of participants lost $>3 \%$ of their BW, $27 \%$ of participants gained $>3 \%$ of their BW and $49 \%$ were weight-maintainers (within $\pm 3 \%$ of baseline weight). Mean changes in aLM were a decrease of 0.57 (SD 0.95) $\mathrm{kg}$ in weight losers and 0.27 (SD $0.85) \mathrm{kg}$ in weight maintainers and an increase of 0.19 (SD $1 \cdot 2) \mathrm{kg}$ among weight gainers. There were no significant differences in baseline characteristics between intervention and control groups (see Supplementary Table S1).
At baseline in model 3 energy-adjusted TP was positively associated with LM, aLM and trunk LM $(\beta \geq 0.05 ; P \leq$ 0.014). AP intake $(\mathrm{g} / \mathrm{d})$ was positively associated with $\mathrm{LM}$ and trunk LM $(\beta \geq 0.08 ; P \leq 0.010)$ (Table 2). AP intake was associated also with aLM in models 1 and 2; however, the association was no longer significant in model 3 after controlling for FM. No significant association was observed for PP intake except a non-significant association with trunk LM ( $\beta=0.06 ; P=0.083)$. Results were independent of FM. In the quartile analysis of protein intakes at baseline, women in higher quartiles of TP and AP, but not PP, had significantly greater LM, aLM and trunk LM $\left(P_{\text {trend }} \leq 0.026\right)$ (data not shown).

Results for the prospective analysis are presented separately between intervention and control groups as well as the total population in Table 3. The interaction between energyadjusted TP, AP and PP intake (g/d) and vitamin D and Ca supplementation was not significant $(P \geq 0.730)$. In model 3 , in the intervention group energy-adjusted TP and AP but not PP intakes $(\mathrm{g} / \mathrm{d})$ were significantly associated with changes in LM and aLM $(\beta \geq 0.22 ; P=0.001)$ over 3 years of followup. No significant association was observed in the control group except that PP was non-significantly associated with aLM change $(\beta=0.11 ; P=0.082)$. In the total population in model 3, TP and AP were positively associated with LM and aLM changes over 3 years of follow-up $(\beta \geq 0.09 ; P \leq$ $0 \cdot 041)$. TP and AP were non-significantly associated also with trunk LM change $(\beta=0.08 ; P \leq 0.088)$. PP intake in the total population was positively associated with aLM change $(\beta=0.09 ; P=0.035)$ and non-significantly associated with LM change $(\beta=0.09 ; P \leq 0.056)$ over 3 years of follow-up.

In a follow-up analysis using quartiles of protein intakes in the intervention group, women in the highest quartiles of TP and AP intakes had significantly increased LM and aLM $\left(P_{\text {trend }} \leq 0.001\right)$ as compared with those in the lower quartiles, while no such association was observed for PP intake. No significant association was observed in the control group. Further, in the total population, a non-significant association was observed between higher quartiles of TP and aLM change $\left(P_{\text {trend }}=0.079\right)$ and PP intake was significantly associated with less decline in aLM $\left(P_{\text {trend }}=0.027\right)$ (data not shown).

The association of energy-adjusted TP ( $\mathrm{g} / \mathrm{d})$ with LM changes was further evaluated according to weight-change status. Weight change and energy-adjusted TP interactions were significant $\left(P_{\text {interaction }}<0 \cdot 001\right)$. Among weight maintainers, energy-adjusted TP $(\mathrm{g} / \mathrm{d})$ was associated with change in LM and aLM and trunk LM $(\beta \geq 0 \cdot 13 ; P \leq 0 \cdot 020)$ (Table 4).

\section{Discussion}

The primary findings of this study were that at baseline higher energy-adjusted TP and AP intakes were positively associated with LM and trunk LM, and that TP intake was also associated with greater aLM. Follow-up results showed that in the intervention group as well as the total population higher TP and AP intakes were positively associated with changes in LM and aLM over 3 years of follow-up, while no significant association was observed in the control group. No such association 
Table 1. Baseline characteristics of participants across quartiles of energy-adjusted total protein intake ( $\mathrm{g} / \mathrm{d}$ ) (Mean values and standard deviations; percentages)

\begin{tabular}{|c|c|c|c|c|c|c|c|c|c|}
\hline \multirow[b]{2}{*}{ Characteristics } & \multicolumn{2}{|c|}{$\begin{array}{c}\text { Quartile } 1(<54.73 \\
\text { g/d) }(n 138)\end{array}$} & \multicolumn{2}{|c|}{$\begin{array}{c}\text { Quartile } 2(54.73- \\
66.0 \mathrm{~g} / \mathrm{d})(n 139)\end{array}$} & \multicolumn{2}{|c|}{$\begin{array}{c}\text { Quartile } 3(66-80 \cdot 3 \\
\text { g/d) }(n 139)\end{array}$} & \multicolumn{2}{|c|}{$\begin{array}{l}\text { Quartile } 4 \text { (>80.3 g/ } \\
\text { d) }(n 138)\end{array}$} & \multirow[b]{2}{*}{$P^{\star}$} \\
\hline & Mean & SD & Mean & SD & Mean & SD & Mean & SD & \\
\hline \multicolumn{10}{|l|}{ Demographics } \\
\hline Age (years) & $68 \cdot 1$ & 1.9 & $67 \cdot 9$ & 1.8 & $67 \cdot 6$ & 1.7 & $67 \cdot 8$ & 1.9 & 0.078 \\
\hline Weight (kg) & $71 \cdot 2$ & $12 \cdot 2$ & 73.7 & 11.9 & 71.5 & $11 \cdot 3$ & 73.43 & $12 \cdot 7$ & 0.014 \\
\hline Height (cm) & $157 \cdot 9$ & 5.6 & $158 \cdot 4$ & 5.5 & $159 \cdot 4$ & $4 \cdot 8$ & $158 \cdot 7$ & $5 \cdot 3$ & 0.139 \\
\hline BMI $\left(\mathrm{kg} / \mathrm{m}^{2}\right)$ & $27 \cdot 2$ & 4.6 & $26 \cdot 8$ & 3.6 & $27 \cdot 8$ & $4 \cdot 1$ & $28 \cdot 0$ & $4 \cdot 2$ & 0.085 \\
\hline Smoking status (\%) & & & & & & & & & 0.194 \\
\hline Never & 83.5 & & $85 \cdot 3$ & & 79.9 & & $83 \cdot 2$ & & \\
\hline Former & $9 \cdot 0$ & & $10 \cdot 3$ & & $15 \cdot 8$ & & 13.9 & & \\
\hline Current & $7 \cdot 5$ & & 4.4 & & $4 \cdot 3$ & & 2.9 & & \\
\hline Portions of alcohol/week $(n)$ & 3.0 & 0.7 & 2.9 & 0.6 & 3.0 & 0.6 & 4.4 & 0.7 & 0.081 \\
\hline Physical activity level (\%)† & & & & & & & & & 0.660 \\
\hline Passive & $39 \cdot 1$ & & 33.8 & & $40 \cdot 3$ & & 39.9 & & \\
\hline Active & 60.9 & & $66 \cdot 2$ & & $59 \cdot 7$ & & $60 \cdot 1$ & & \\
\hline Hormone therapy use (\%) & & & & & & & & & 0.008 \\
\hline Never used & $54 \cdot 0$ & & 58.7 & & $54 \cdot 0$ & & 58.7 & & \\
\hline Used & $46 \cdot 0$ & & $41 \cdot 3$ & & $46 \cdot 0$ & & $41 \cdot 3$ & & \\
\hline \multicolumn{10}{|l|}{ Body composition } \\
\hline $\mathrm{FM}(\mathrm{kg})$ & $28 \cdot 0$ & $9 \cdot 3$ & $28 \cdot 3$ & $7 \cdot 7$ & $29 \cdot 6$ & 8.7 & $29 \cdot 8$ & $8 \cdot 7$ & 0.211 \\
\hline LM (kg) & $39 \cdot 1$ & $4 \cdot 3$ & $40 \cdot 1$ & 3.8 & $40 \cdot 3$ & $4 \cdot 3$ & $41 \cdot 2$ & 4.6 & 0.003 \\
\hline aLM (kg) & $16 \cdot 7$ & $1 \cdot 8$ & $17 \cdot 0$ & 1.9 & $17 \cdot 1$ & $2 \cdot 0$ & $17 \cdot 3$ & 2.0 & 0.027 \\
\hline Trunk LM (kg) & $19 \cdot 5$ & $2 \cdot 6$ & $19 \cdot 6$ & 1.9 & $20 \cdot 3$ & 2.4 & $20 \cdot 4$ & $2 \cdot 6$ & 0.001 \\
\hline FM:LM ratio & 0.70 & & 0.71 & & 0.72 & & 0.72 & & 0.774 \\
\hline \multicolumn{10}{|l|}{ Dietary intakes } \\
\hline Total energy (kJ/d) & 5091 & 1108 & 6150 & 1071 & 6907 & 1037 & 8083 & 1238 & 0.036 \\
\hline Fat (\% energy) & $30 \cdot 8$ & 5.5 & $31 \cdot 0$ & 5.4 & $31 \cdot 2$ & 5.9 & $31 \cdot 1$ & $5 \cdot 4$ & $<0.001$ \\
\hline Fat $(g / d)$ & 55.6 & 9.9 & $54 \cdot 1$ & $10 \cdot 1$ & $51 \cdot 3$ & 8.9 & $66 \cdot 8$ & $17 \cdot 6$ & 0.005 \\
\hline Carbohydrate (\% energy) & $50 \cdot 8$ & $6 \cdot 3$ & $49 \cdot 6$ & $5 \cdot 1$ & 45.4 & $5 \cdot 8$ & 49.5 & $52 \cdot 7$ & $<0.001$ \\
\hline Carbohydrate $(\mathrm{g} / \mathrm{d})$ & $204 \cdot 0$ & 51.5 & $190 \cdot 5$ & 45.5 & $187 \cdot 6$ & $48 \cdot 0$ & $193 \cdot 3$ & $47 \cdot 8$ & 0.028 \\
\hline Protein (\% energy) & $16 \cdot 0$ & 3.0 & $17 \cdot 0$ & 2.7 & 18.0 & 3.0 & $19 \cdot 4$ & $3 \cdot 1$ & $<0.001$ \\
\hline Protein $(\mathrm{g} / \mathrm{d})$ & $47 \cdot 0$ & $7 \cdot 7$ & $60 \cdot 6$ & $3 \cdot 2$ & $72 \cdot 7$ & $4 \cdot 3$ & $92 \cdot 0$ & 10.5 & $<0.001$ \\
\hline Animal protein $(\mathrm{g} / \mathrm{d})$ & $24 \cdot 7$ & 5.9 & $35 \cdot 2$ & 2.0 & 42.5 & 2.4 & $54 \cdot 3$ & 6.7 & $<0.001$ \\
\hline Vegetable protein (g/d) & 23.5 & 4.4 & $24 \cdot 0$ & 4.5 & 24.4 & $4 \cdot 0$ & $24 \cdot 1$ & $4 \cdot 2$ & 0.451 \\
\hline Protein (g/kg body weight) & 0.79 & $0 \cdot 24$ & 0.90 & 0.23 & 0.96 & 0.27 & $1 \cdot 18$ & 0.29 & $<0.001$ \\
\hline
\end{tabular}

FM, fat mass; LM, lean mass; aLM, appendicular LM.

${ }^{*}$ ANOVA or $\chi^{2}$ tests were used to evaluate the distribution.

† Passive: no mobility and exercise $\leq 2$ times/week; active: no mobility restriction and exercise $>2$ times/week.

Table 2. Cross-sectional association of protein intake and total lean mass (LM), appendicular LM (aLM) and trunk LM ( $n$ 554)

( $\beta$ Coefficients with their standard errors)

\begin{tabular}{|c|c|c|c|c|c|c|c|c|c|}
\hline & \multicolumn{3}{|c|}{ LM (kg) } & \multicolumn{3}{|c|}{ aLM (kg) } & \multicolumn{3}{|c|}{ Trunk LM (kg) } \\
\hline & $\beta$ & SE & $P$ & $\beta$ & SE & $P$ & $\beta$ & SE & $P$ \\
\hline \multicolumn{10}{|c|}{ Total protein $(\mathrm{g} / \mathrm{d})$} \\
\hline Model $1^{\star}$ & 0.12 & 0.01 & 0.001 & 0.08 & 0.01 & 0.017 & 0.13 & 0.82 & 0.001 \\
\hline Model $2 \dagger$ & 0.15 & 0.01 & $<0.001$ & 0.09 & 0.08 & 0.014 & 0.16 & 0.81 & $<0.001$ \\
\hline Model 3ł & 0.09 & 0.01 & 0.006 & 0.05 & 0.08 & 0.014 & 0.10 & 0.94 & 0.002 \\
\hline \multicolumn{10}{|c|}{ Animal protein§(g/d) } \\
\hline Model 1 & 0.12 & 0.01 & 0.001 & 0.08 & 0.01 & 0.020 & 0.13 & 0.83 & 0.001 \\
\hline Model 2 & 0.15 & 0.01 & $<0.001$ & 0.11 & 0.01 & 0.003 & 0.16 & 0.81 & $<0.001$ \\
\hline Model 3 & 0.08 & 0.01 & 0.010 & 0.04 & 0.01 & 0.163 & 0.10 & 0.88 & 0.003 \\
\hline \multicolumn{10}{|c|}{ Plant proteinll (g/d) } \\
\hline Model 1 & 0.02 & 0.03 & 0.530 & 0.01 & 0.01 & 0.732 & 0.02 & 0.22 & 0.546 \\
\hline Model 2 & 0.01 & 0.03 & 0.726 & -0.01 & 0.01 & 0.984 & 0.01 & 0.22 & 0.718 \\
\hline Model 3 & 0.05 & 0.04 & 0.100 & 0.03 & 0.02 & 0.290 & 0.06 & 0.24 & 0.083 \\
\hline
\end{tabular}

* Model 1 was adjusted for age, total energy intake and baseline height and study group.

† Model 2 was adjusted for variables in model 1 plus smoking status, alcohol use per week, physical activity level and hormone therapy use.

† Model 3 was adjusted for variables in model 2 plus baseline fat mass.

$\S$ Models for animal protein were also adjusted for plant protein intake.

॥ Models for plant protein were also adjusted for animal protein intake. 
Table 3. Prospective association of protein intake and changes in total lean mass (LM), appendicular LM (aLM) and trunk LM between intervention and control groups and the total population

( $\beta$ Coefficients with their standard errors)

\begin{tabular}{|c|c|c|c|c|c|c|c|c|c|}
\hline & \multicolumn{3}{|c|}{ LM (kg) } & \multicolumn{3}{|c|}{ aLM (kg) } & \multicolumn{3}{|c|}{ Trunk LM (kg) } \\
\hline & $\beta$ & SE & $P$ & $\beta$ & SE & $P$ & $\beta$ & SE & $P$ \\
\hline \multicolumn{10}{|c|}{ Total protein $(\mathrm{g} / \mathrm{d})$} \\
\hline \multicolumn{10}{|c|}{ Intervention group ( $n$ 270) } \\
\hline Model $1^{*}$ & 0.19 & 8.52 & 0.003 & 0.20 & 0.01 & 0.001 & 0.09 & 6.05 & 0.032 \\
\hline Model $2 \dagger$ & 0.27 & $8 \cdot 27$ & $<0.001$ & 0.27 & 0.01 & $<0.001$ & 0.15 & 5.95 & 0.024 \\
\hline Model 3‡ & 0.22 & $10 \cdot 70$ & 0.001 & 0.24 & 0.01 & 0.001 & 0.10 & $7 \cdot 60$ & 0.125 \\
\hline \multicolumn{10}{|c|}{ Control group (n 282) } \\
\hline Model 1 & -0.03 & 9.97 & 0.559 & -0.03 & 0.01 & 0.539 & 0.01 & 5.82 & 0.955 \\
\hline Model 2 & -0.40 & $9 \cdot 30$ & 0.538 & -0.51 & 0.01 & 0.429 & 0.01 & 6.05 & 0.877 \\
\hline Model 3 & -0.07 & $12 \cdot 80$ & 0.275 & -0.05 & 0.01 & 0.360 & -0.03 & $8 \cdot 30$ & 0.548 \\
\hline \multicolumn{10}{|c|}{ Total population ( $n 552$ ) } \\
\hline Model 1 & 0.07 & 0.06 & 0.115 & 0.06 & 0.04 & 0.098 & 0.05 & 0.04 & 0.276 \\
\hline Model 2 & 0.09 & 0.06 & 0.035 & 0.08 & 0.04 & 0.050 & 0.08 & 0.04 & 0.075 \\
\hline Model 3 & 0.10 & 0.01 & 0.032 & 0.09 & 0.04 & 0.041 & 0.08 & 0.04 & 0.081 \\
\hline \multicolumn{10}{|c|}{ Animal protein§(g/d) } \\
\hline \multicolumn{10}{|c|}{ Intervention group ( $n$ 270) } \\
\hline Model 1 & 0.17 & 8.53 & 0.004 & 0.19 & 0.01 & 0.001 & 0.08 & 6.08 & 0.068 \\
\hline Model 2 & 0.27 & 8.26 & $<0.001$ & 0.27 & 0.01 & $<0.001$ & 0.14 & 6.95 & 0.027 \\
\hline Model 3 & 0.22 & $10 \cdot 40$ & 0.001 & 0.24 & 0.01 & 0.001 & 0.09 & $7 \cdot 10$ & 0.151 \\
\hline \multicolumn{10}{|c|}{ Control group ( $n$ 282) } \\
\hline Model 1 & -0.03 & 8.96 & 0.557 & -0.04 & 0.01 & 0.528 & 0.01 & 5.90 & 0.952 \\
\hline Model 2 & -0.04 & $9 \cdot 28$ & 0.539 & -0.05 & 0.01 & 0.430 & 0.10 & 6.05 & 0.874 \\
\hline Model 3 & -1.03 & 11.90 & 0.301 & -0.06 & 0.07 & 0.334 & -0.03 & $7 \cdot 70$ & 0.625 \\
\hline \multicolumn{10}{|c|}{ Total population ( $n$ 552) } \\
\hline Model 1 & 0.06 & 0.06 & 0.142 & 0.07 & 0.04 & 0.092 & 0.05 & 0.04 & 0.287 \\
\hline Model 2 & 0.09 & 0.06 & 0.049 & 0.08 & 0.04 & 0.047 & 0.08 & 0.04 & 0.080 \\
\hline Model 3 & 0.10 & 0.06 & 0.037 & 0.09 & 0.04 & 0.037 & 0.08 & 0.04 & 0.088 \\
\hline \multicolumn{10}{|c|}{ Plant proteinll (g/d) } \\
\hline \multicolumn{10}{|c|}{ Intervention group ( $n$ 270) } \\
\hline Model 1 & 0.09 & $22 \cdot 12$ & 0.124 & 0.09 & 0.01 & 0.098 & 0.05 & $15 \cdot 79$ & 0.430 \\
\hline Model 2 & 0.05 & 22.01 & 0.436 & 0.03 & 0.01 & 0.608 & 0.03 & $15 \cdot 84$ & 0.575 \\
\hline Model 3 & 0.10 & 0.02 & 0.137 & 0.08 & 0.01 & 0.182 & 0.06 & 0.15 & 0.360 \\
\hline \multicolumn{10}{|c|}{ Control group (n 282) } \\
\hline Model 1 & 0.06 & 24.86 & 0.323 & 0.09 & 0.01 & 0.126 & 0.01 & $16 \cdot 35$ & 0.935 \\
\hline Model 2 & 0.09 & 26.57 & 0.160 & 0.11 & 0.01 & 0.090 & 0.03 & $17 \cdot 33$ & 0.597 \\
\hline Model 3 & 0.09 & 0.02 & 0.158 & 0.11 & 0.01 & 0.082 & 0.03 & 0.17 & 0.601 \\
\hline \multicolumn{10}{|c|}{ Total population ( $n 552)$} \\
\hline Model 1 & -0.81 & 0.36 & 0.223 & -0.15 & 0.21 & 0.019 & -0.04 & $2 \cdot 4$ & 0.482 \\
\hline Model 2 & 0.09 & 0.17 & 0.063 & 0.09 & 0.01 & 0.039 & 0.04 & $1 \cdot 11$ & 0.327 \\
\hline Model 3 & 0.09 & 0.17 & 0.056 & 0.09 & 0.01 & 0.035 & 0.04 & 1.11 & 0.334 \\
\hline
\end{tabular}

* Model 1 was adjusted for age, total energy intake and baseline height and study group.

† Model 2 was adjusted for variables in model 1 plus smoking status, alcohol use per week, physical activity level and hormone therapy use.

$\ddagger$ Model 3 was adjusted for variables in model 2 plus baseline fat mass.

$\S$ Models for animal protein were also adjusted for plant protein intake.

II Models for plant protein were also adjusted for animal protein intake.

was observed for PP intake except that in the total population PP intake was significantly associated with less decline in aLM over 3 years of follow-up. These associations remained significant even after adjusting for FM. Further, among weight maintainers TP intake was positively associated with LM, aLM and trunk LM changes.

Houston et al. showed that among women aged 70-79 years ( $n$ 2066), those with higher protein intake (19\% of total energy

Table 4. Association of total protein intake ( $\mathrm{g} / \mathrm{d})$ and changes of lean mass (LM), appendicular LM and trunk LM by weight change status ( $n$ 551) ( $\beta$ Coefficients with their standard errors)

\begin{tabular}{|c|c|c|c|c|c|c|c|c|c|c|}
\hline & \multirow[b]{2}{*}{$n$} & \multicolumn{3}{|c|}{ LM (kg) } & \multicolumn{3}{|c|}{ aLM (kg) } & \multicolumn{3}{|c|}{ Trunk LM (kg) } \\
\hline & & $\beta$ & SE & $P^{\star}$ & $\beta$ & SE & $P$ & $\beta$ & SE & $P$ \\
\hline Weight losers $†$ & 180 & 0.10 & 0.01 & 0.237 & 0.11 & 0.01 & 0.150 & 0.03 & 0.01 & 0.704 \\
\hline Weight maintainers & 278 & 0.29 & 0.07 & 0.001 & 0.13 & 0.01 & 0.020 & 0.17 & 0.01 & 0.005 \\
\hline Weight gainers & 96 & -0.11 & 0.02 & 0.321 & -0.27 & 0.01 & 0.783 & -0.09 & 0.01 & 0.445 \\
\hline
\end{tabular}

* Adjusted for age, total energy intake, baseline LM, aLM and trunk LM, height, smoking status, alcohol portions per week, physical activity level, hormone therapy use and study group.

† Those who lost over $3 \%$ of their baseline weight during the 3 years of follow-up were classified as weight losers, those who gained over $3 \%$ as weight gainers, and those with moderate change as weight maintainers. 
intake) lost $40 \%$ less LM as compared with those with lower intake (11\% of total energy intake) over a 3-year follow-up ${ }^{(5)}$. Similarly, Meng et al. found that elderly women with higher TP intake (average $>1.6 \mathrm{~g} / \mathrm{kg} \mathrm{BW}$ or $20.0 \%$ of energy) had higher LM as compared with those with lower protein intake (average $0.85 \mathrm{~g} / \mathrm{kg} \mathrm{BW}$ or $18.0 \%$ of energy) ${ }^{(7)}$. The results from the present study were consistent with those previous studies suggesting that higher protein intake is beneficial to $\mathrm{LM}^{(5-8,28)}$.

For older people (>65 years) to maintain and regain muscle mass and function, an average daily intake at least in the range of 1.0 to $1.2 \mathrm{~g} / \mathrm{kg} \mathrm{BW}$ is recommended ${ }^{(29,30)}$, which is higher than the current RDA $(0.8 \mathrm{~g} / \mathrm{kg} \mathrm{BW})^{(31)}$. A preponderance of evidence now suggests that ageing might result in the stimulation of MPS becoming resistant to the anabolic effect of hyperaminoacidaemia, particularly at lower protein intakes ${ }^{(10)}$. The decreased MPS might partially be explained by decreased mammalian target of rapamycin and the $70-\mathrm{kDa}$ ribosomal protein S6 kinase signalling ${ }^{(32)}$, and changes in positive regulators like insulin-like growth factor 1 and negative regulators (e.g. adenosine monophosphate-activated protein kinase) of this pathway ${ }^{(33,34)}$. AP contains essential amino acids, which trigger the aforementioned signalling pathways, enhancing protein accretion and $\mathrm{LM}^{(34)}$.

Only a few studies have examined the effect of protein source on body composition in older adults ${ }^{(5,6,9)}$. In a study by Sahni et al. in men and women aged 59 (SD 9) years TP intake was 80 (SD 27) g/d in men and 76 (SD 26) g/d in women. In men and women, leg LM was higher in participants in the highest quartile of TP and AP intake compared with those in the lowest quartiles of intake ${ }^{(6)}$. PP intake was not associated with LM in either sex. Although plant-based diets are low in certain essential amino acids, they have been linked with higher $\mathrm{LM}^{(17,35)}$. Our data suggest accordingly that AP but not PP was associated with greater LM; however, PP was associated with increased aLM in the total population over 3 years of follow-up. Thus, the dietary protein quality (AP v. PP) intake in relation to health outcomes and LM needs to be further clarified.

Vitamin D can potentially affect LM through different mechanisms which are yet not fully elucidated ${ }^{(14,15)}$. It has been suggested that vitamin $\mathrm{D}$ deficiency is linked with muscle weakness. The presence of vitamin D receptor in muscle tissue cells is yet a matter of debate ${ }^{(13,36)}$. Previous findings regarding the effect of vitamin D supplementation on LM are inconclusive ${ }^{(11,12)}$. A recent meta-analysis suggested that vitamin D has no significant effect on $\mathrm{LM}^{(11)}$. A separate investigation in the present data showed no significant effect of vitamin D (800 IU; $20 \mu \mathrm{g}$ ) and Ca supplementation on LM (M Isanejad, J Sirola, H Kröger and $\mathrm{T}$ Rikkonen, unpublished results). Furthermore, some evidence suggests that vitamin D and protein intake might have a synergic effect on increasing $\mathrm{LM}^{(15,37)}$. LM loss during ageing my partially be explained by the decreased ability of muscle to respond to anabolic stimuli provided by dietary protein through decreased MPS to physiological concentrations of amino acids and insulin ${ }^{(38)}$. Of particular interest, vitamin D deficiency was associated with insulin resistance in vivo ${ }^{(39)}$, while vitamin $\mathrm{D}$ treatments have been linked to an increased expression of insulin receptor in skeletal muscle ${ }^{(15,40)}$. The present study showed that the association of TP and AP with changes in LM and aLM was stronger in those women who received the vitamin D and Ca supplementation. Although there were no differences in the baseline characteristics between the intervention and control groups, it is possible that there were other modifying factors. To the best of our knowledge this was the first cohort study to evaluate the interaction between vitamin D and $\mathrm{Ca}$ supplementation and protein intake with LM and further studies are warranted.

Although data to support guidelines for weight loss in the elderly are limited, one of the main targets is the preservation of LM by adequate protein intake ${ }^{(16)}$. Previously an intervention study has shown that a diet with high protein intake (35\% of energy) was associated with preservation of LM during weight loss ${ }^{(41)}$. Our data suggest that associations of TP intake and LM, aLM and trunk LM were significant in weight maintainers when weight changes do not confound. Therefore, these findings suggest that it is worth paying attention to the role of dietary protein intake in weight change among the ageing population.

The strength of the present study was that all the body composition measurements were available at baseline and over a 3 -year period. We performed a careful adjustment for potential known confounders; however, there might be other factors that were not captured in this study. To adjust for body size as an important modifying factor for LM, a variety of methods have been used, and we chose baseline height which has been applied and used before ${ }^{(5,7,42)}$. Worthy of note is that aLM provides a measure in which the component of muscle is relatively large.

A limitation of this study was that the study population consists of only elderly women and therefore caution should be taken when generalising the findings to elderly men. However, in previous studies when exploring associations between protein intake and LM, significant associations were observed similarly for men and women ${ }^{(5,6)}$. It would be beneficial for future studies to explore the association of protein intake and LM change in both males and females. The 3-d dietary records method has been described as a suitable instrument for assessing energy and protein intake in elderly people ${ }^{(43,44)}$, which has been also used and applied to measure AP and PP intake ${ }^{(8)}$. The latter study has also been validated against urinary nitrogen studies in both community-dwelling and institutionalised elderly people ${ }^{(44)}$. However, errors in recording and change in dietary intake as well as type of protein intake are not avoidable, but the distribution of errors is unlikely to be related to the outcome. The dietary intake assessment was obtained only at baseline which may be insufficient to capture long-term dietary exposures. Information of intentionality of weight loss during the 3 years of follow-up was not available; therefore, it might be possible that those who lost weight over this period had generally lower inferior health condition as compared with weight maintainers or weight gainers. Lastly, causal associations cannot be obtained due to the observational nature of this study.

In conclusion, our findings support the current evidence that higher TP and in particular AP intakes are beneficial in 
preserving LM. A remarkable finding of this study was that the associations of TP, AP with increased LM were more apparent among elderly women who maintained their weight and received vitamin $\mathrm{D}$ and $\mathrm{Ca}$ supplementation. Since dietary protein intake, vitamin $\mathrm{D}$ and weight change are important health concerns of ageing, our results might underscore an important message for public health.

\section{Supplementary material}

To view supplementary material for this article, please visit http://dx.doi.org/10.1017/jns.2015.31

\section{Acknowledgements}

The OSTPRE-FPS was supported by the Finnish Cultural Foundation (Hulda Tossavainen Foundation; H. K.), the Sigrid Juselius Foundation (H. K. and T. R.), Academy of Finland (M. T.) and a Kuopio University Hospital EVO grant.

The authors declare no conflict of interests.

The authors' responsibilities were as follows. M. I.: study design, analysis and interpretation of the data and drafting of the manuscript; A. T. E.: study design, analysis and interpretation of the data and critical revision of the manuscript; J. M. and J. S.: interpretation of the data and critical revision of the manuscript; H. K., T. R. and M. T.: critically revised the final manuscript for important intellectual content.

\section{References}

1. Muller MJ, Geisler C, Pourhassan M, et al. (2014) Assessment and definition of lean body mass deficiency in the elderly. Eur J Clin Nutr 68, 1220-1227.

2. Cruz-Jentoft AJ, Baeyens JP, Bauer JM, et al. (2010) Sarcopenia: European consensus on definition and diagnosis: Report of the European Working Group on Sarcopenia in Older People. Age Ageing 39, 412-423.

3. Hughes VA, Frontera WR, Roubenoff R, et al. (2002) Longitudinal changes in body composition in older men and women: role of body weight change and physical activity. Am J Clin Nutr 76, 473-481.

4. Evans WJ (2010) Skeletal muscle loss: cachexia, sarcopenia, and inactivity. Am J Clin Nutr 91, 1123S-1127S.

5. Houston DK, Nicklas BJ, Ding J, et al. (2008) Dietary protein intake is associated with lean mass change in older, community-dwelling adults: the Health, Aging, and Body Composition (Health ABC) Study. Am J Clin Nutr 87, 150-155.

6. Sahni S, Mangano KM, Hannan MT, et al. (2015) Higher protein intake is associated with higher lean mass and quadriceps muscle strength in adult men and women. J Nutr 145, 1569-1575.

7. Meng X, Zhu K, Devine A, et al. (2009) A 5-year cohort study of the effects of high protein intake on lean mass and BMC in elderly postmenopausal women. J Bone Miner Res 24, 1827-1834.

8. Lord C, Chaput JP, Aubertin-Leheudre M, et al. (2007) Dietary animal protein intake: association with muscle mass index in older women. J Nutr Health Aging 11, 383-387.

9. Aubertin-Leheudre M \& Adlercreutz H (2009) Relationship between animal protein intake and muscle mass index in healthy women. Br J Nutr 102, 1803-1810.

10. Paddon-Jones D \& Rasmussen BB (2009) Dietary protein recommendations and the prevention of sarcopenia. Curr Opin Clin Nutr Metab Care 12, 86-90.
11. Beaudart C, Buckinx F, Rabenda V, et al. (2014) The effects of vitamin D on skeletal muscle strength, muscle mass, and muscle power: a systematic review and meta-analysis of randomized controlled trials. J Clin Endocrinol Metab 99, 4336-4345.

12. Mithal A, Bonjour JP, Boonen S, et al. (2013) Impact of nutrition on muscle mass, strength, and performance in older adults. Osteoporos Int 24, 1555-1566.

13. Bischoff-Ferrari HA, Borchers M, Gudat F, et al. (2004) Vitamin D receptor expression in human muscle tissue decreases with age. J Bone Miner Res 19, 265-269.

14. Rizzoli R, Stevenson JC, Bauer JM, et al. (2014) The role of dietary protein and vitamin $\mathrm{D}$ in maintaining musculoskeletal health in postmenopausal women: a consensus statement from the European Society for Clinical and Economic Aspects of Osteoporosis and Osteoarthritis (ESCEO). Maturitas 79, 122-132.

15. Salles J, Chanet A, Giraudet C, et al. (2013) $1,25(\mathrm{OH})_{2}$-vitamin $\mathrm{D}_{3}$ enhances the stimulating effect of leucine and insulin on protein synthesis rate through Akt/PKB and mTOR mediated pathways in murine C2C12 skeletal myotubes. Mol Nutr Food Res 57, 2137 2146.

16. Mathus-Vliegen EM \& Obesity Management Task Force of the European Association for the Study of Obesity (2012) Prevalence, pathophysiology, health consequences and treatment options of obesity in the elderly: a guideline. Obes Facts 5, 460-483.

17. Pedersen AN \& Cederholm $\mathrm{T}$ (2014) Health effects of protein intake in healthy elderly populations: a systematic literature review. Food Nutr Res 58, 10.3402/fnr.v58.23364.

18. Karkkainen M, Tuppurainen M, Salovaara K, et al. (2010) Effect of calcium and vitamin $\mathrm{D}$ supplementation on bone mineral density in women aged 65-71 years: a 3-year randomized population-based trial (OSTPRE-FPS). Osteoporos Int 21, 2047-2055.

19. Jarvinen R, Tuppurainen M, Erkkila AT, et al. (2012) Associations of dietary polyunsaturated fatty acids with bone mineral density in elderly women. Eur J Clin Nutr 66, 496-503.

20. Lohman M, Tallroth K, Kettunen JA, et al. (2009) Reproducibility of dual-energy X-ray absorptiometry total and regional body composition measurements using different scanning positions and definitions of regions. Metabolism 58, 1663-1668.

21. Kroger H, Heikkinen J, Laitinen K, et al. (1992) Dual-energy X-ray absorptiometry in normal women: a cross-sectional study of 717 Finnish volunteers. Osteoporos Int 2, 135-140.

22. Erkkila AT, Jarvinen R, Karvonen H, et al. (2012) Validation of a semi-quantitative FFQ using food records as a reference in older women in the Kuopio Fracture Prevention Study (OSTPREFPS). Public Health Nutr 15, 635-639.

23. Department of Health (editor) (1991). Dietary Reference Values for Food Energy and Nutrients for the United Kingdom. London: HMSO.

24. Goldberg GR, Black AE, Jebb SA, et al. (1991) Critical evaluation of energy intake data using fundamental principles of energy physiology: 1. Derivation of cut-off limits to identify under-recording. Eur J Clin Nutr 45, 569-581.

25. Black AE (2000) Critical evaluation of energy intake using the Goldberg cut-off for energy intake:basal metabolic rate. A practical guide to its calculation, use and limitations. Int J Obes Relat Metab Disord 24, 1119-1130.

26. Willett WC, Howe GR \& Kushi LH (1997) Adjustment for total energy intake in epidemiologic studies. Am J Clin Nutr 65, 1220S-1228S; discussion 1229S-1231S.

27. Visser M, Harris TB, Langlois J, et al. (1998) Body fat and skeletal muscle mass in relation to physical disability in very old men and women of the Framingham Heart Study. J Gerontol A Biol Sci Med Sci 53, M214-M221.

28. Geirsdottir OG, Arnarson A, Ramel A, et al. (2013) Dietary protein intake is associated with lean body mass in community-dwelling older adults. Nutr Res 33, 608-612.

29. Bauer J, Biolo G, Cederholm T, et al. (2013) Evidence-based recommendations for optimal dietary protein intake in older people: a position paper from the PROT-AGE Study Group. J Am Med Dir Assoc 14, 542-559. 
30. Nordic Council of Ministers (2014) Nordic Nutrition Recommendations 2012. Integrating Nutrition and Physical Activity, 5th ed. Copenhagen: Nordic Council of Ministers.

31. Suominen MH, Jyvakorpi SK, Pitkala KH, et al. (2014) Nutritional guidelines for older people in Finland. J Nutr Health Aging 18, 861-867.

32. Eley HL, Russell ST, Baxter JH, et al. (2007) Signaling pathways initiated by $\beta$-hydroxy- $\beta$-methylbutyrate to attenuate the depression of protein synthesis in skeletal muscle in response to cachectic stimuli. Am J Physiol Endocrinol Metab 293, E923-E931.

33. Katsanos CS, Kobayashi H, Sheffield-Moore M, et al. (2006) A high proportion of leucine is required for optimal stimulation of the rate of muscle protein synthesis by essential amino acids in the elderly. Am J Physiol Endocrinol Metab 291, E381-E387.

34. Milner RD (1969) Stimulation of insulin secretion in vitro by essential aminoacids. Lancet $\mathbf{i}, 1075-1076$.

35. Han S, Chee K \& Cho S (2015) Nutritional quality of rice bran protein in comparison to animal and vegetable protein. Food Chem 172, 766-769.

36. Wang Y \& DeLuca HF (2011) Is the vitamin D receptor found in muscle? Endocrinology 152, 354-363.

37. Verreijen AM, Verlaan S, Engberink MF, et al. (2015) A high whey protein-, leucine-, and vitamin D-enriched supplement preserves muscle mass during intentional weight loss in obese older adults: a double-blind randomized controlled trial. Am J Clin Nutr 101, 279-286.
38. Dardevet D, Sornet C, Bayle G, et al. (2002) Postprandial stimulation of muscle protein synthesis in old rats can be restored by a leucine-supplemented meal. J Nutr 132, 95-100.

39. Combaret L, Dardevet D, Rieu I, et al. (2005) A leucinesupplemented diet restores the defective postprandial inhibition of proteasome-dependent proteolysis in aged rat skeletal muscle. J Physiol 569, 489-499.

40. Calle C, Maestro B \& Garcia-Arencibia M (2008) Genomic actions of 1,25-dihydroxyvitamin $\mathrm{D}_{3}$ on insulin receptor gene expression, insulin receptor number and insulin activity in the kidney, liver and adipose tissue of streptozotocin-induced diabetic rats. $B M C$ Mol Biol 9, 65.

41. Wycherley TP, Buckley JD, Noakes M, et al. (2013) Comparison of the effects of weight loss from a high-protein versus standard-protein energy-restricted diet on strength and aerobic capacity in overweight and obese men. Eur J Nutr 52, 317-325.

42. Kerr DA, Papalia S, Morton A, et al. (2007) Bone mass in young women is dependent on lean body mass. J Clin Densitom 10, 319-326.

43. Luhrmann PM, Herbert BM, Gaster C, et al. (1999) Validation of a self-administered 3-day estimated dietary record for use in the elderly. Eur J Nutr 38, 235-240.

44. Paddon-Jones D, Sheffield-Moore M, Katsanos CS, et al. (2006) Differential stimulation of muscle protein synthesis in elderly humans following isocaloric ingestion of amino acids or whey protein. Exp Gerontol 41, 215-219. 